\title{
Migración y trabajo en Chile. Derribando mitos asociados a los procesos de incorporación laboral en personas migrantes
}

\author{
Migration and Work in Chile. Tearing Down the \\ Myths Associated with the Processes of Labor \\ Incorporation for Migrants
}

\section{Esteban Bakx BermúdeZ}

Area de Desarrollo Familiar Programa de Interculturalidad Municipalidad de La Reina. Av. Alcalde Fernando Castillo Velasco 9750, La Reina, Chile, mail: ebakx@mlareina.cl

\begin{abstract}
Resumen
Chile, en las últimas décadas, ha sido un foco de atracción de flujos migratorios provenientes de diferentes partes del mundo. Los principales motivos de esta migración, se deben al interés que los extranjeros poseen de buscar mejores expectativas laborales en el pais. En este contexto, el presente artículo busca develar que los procesos de búsqueda y de incorporación laboral de personas migrantes están siendo obstaculizados hoy en día por la existencia de ciertos mitos, generados producto del desconocimiento existente tanto por parte del mundo empresarial como por los propios trabajadores migrantes sobre sus deberes y derechos laborales. El artículo busca derribar dichos mitos entregando argumentos y análisis basados en cuerpos legales y estudios atingentes al tema, para así fomentar la incorporación laboral migrante de forma regular, segura y ordenada. Finalmente, se aportan ciertas recomendaciones desde el rol del Trabajo Social, con el objeto de contribuir a la temática en cuestión.
\end{abstract}

Palabras claves: Migración, trabajo, mitos, incorporación laboral.

\begin{abstract}
Chile, in recent decades, has been a focus of attraction of migratory flows from different parts of the world. The main reasons for this migration are due to the interest that foreigners have in seeking better labor prospects in the country. In this context, the present article seeks to reveal that the processes of searching for work and labor incorporation of migrants are being obstructed today by the existence of certain myths, generated as a result of lack of awareness about labor duties and rights on the part of both the business world and the workers themselves. The article seeks to tear down these myths by providing arguments and analyses based on legal bodies and studies relevant to the subject in order to promote the incorporation of migrant labor in a legal, safe and organized manner. Finally, certain recommendations are provided from the discipline of Social Work in order to contribute to the subject in question.
\end{abstract}

Key words: Migration, work, myths, laboral incorporation.

Nota: En relación con el presente artículo se recomienda revisar también el siguiente documento: "COMENTARIO SOBRE EL ARTÍCULO: Migración y trabajo en Chile. Derribando mitos asociados a los procesos de incorporación laboral en personas migrantes", el cual posee una sintesis de la nueva reforma migratoria instalada por el actual gobierno del presidente Sebastián Piñera. Dicha reforma posee diferentes ejes de acción, de los cuales algunos comenzaron a regir en abril del año 2018, alterando los mitos propuestos por el presente artículo. Es por lo anterior que la revisión de estos ejes de acción son clave para poseer una mirada actualizada y clara sobre los procesos de incorporación laboral en personas migrantes en el país hoy en día. 


\section{Presentación}

Las importantes transformaciones políticas, económicas, sociales y culturales que ha debido enfrentar el mundo, y particularmente el continente latinoamericano, han agudizado los procesos migratorios a nivel internacional, viéndose de esta manera la movilidad humana como un fenómeno social cada vez más recurrente y de mayor fuerza.

Chile, en las últimas décadas, producto de su creciente estabilidad política y económica, ha dado paso al desarrollo de nuevos proyectos de vida por parte de extranjeros de diferentes partes del mundo en el país, principalmente de países vecinos como Argentina, Perú, Bolivia, Colombia y Ecuador, impulsados primordialmente tanto por asuntos económicos y, migración forzada, como también por desarrollo personal (Rojas y Silva, 2016, p. 5).

En este contexto, según datos entregados por la Encuesta de Caracterización Socioeconómica Nacional (CASEN-Inmigrantes 2015), es posible encontrar la presencia de 465.319 personas extranjeras en Chile, equivalentes al 2,7\% en relación con el total de la población existente en dicho país (Ministerio de Desarrollo Social, 2016, p. 7). De esta población, cabe mencionar que éstos en su gran mayoría son jóvenes que oscilan en un rango etario entre los 18 y 59 años de edad, con años promedio de escolaridad mayores que la población nacional chilena y con tasas de participación y ocupación laboral superiores a la de las personas nacidas en Chile (Ministerio de Desarrollo Social, 2016, p. 63).

Los datos proporcionados previamente dan a entender que la comunidad migrante residente en Chile responde a una población económicamente activa, motivada de participar en el mercado laboral y contribuir en el desarrollo económico del país, antecedentes sustanciales de tomar en consideración para el análisis de los procesos de incorporación laboral en personas extranjeras.

De esta manera, continuando con los datos proporcionados por la Encuesta CASEN-Inmigrantes 2015, específicamente en lo que respecta a cómo se ha desarrollado la vinculación de la comunidad migrante con el mercado laboral en Chile, es posible rescatar que la tasa de participación laboral de los extranjeros alcanza el $76,7 \%$ por sobre la tasa de las personas nacidas en territorio nacional $(57,7 \%)$, lo que da a entender que la comunidad migrante residente en Chile posee una participación mayormente activa en el mercado laboral, ya sea trabajando o buscando trabajo. Del mismo modo, la comunidad migrante posee una tasa de ocupación laboral equivalente al $72,4 \%$ por sobre la tasa de las personas nacidas en Chile (53,4\%), lo que también da a entender que los extranjeros residentes en el país poseen un nivel de ocupación laboral, ya sea trabajando como dependiente o independiente por un sueldo o salario, mayor que la comunidad chilena (Ministerio de Desarrollo Social, 2016, pp. 63-68). Asimismo, un gran porcentaje del total de extranjeros $(77,7 \%)$ posee contrato o acuerdo de trabajo indefinido, a diferencia de las personas nacidas en Chile que alcanzan un 71,5\% y además un gran porcentaje de ellos $(69,3 \%)$ cotiza en un sistema previsional a diferencia de la comunidad chilena que alcanza un porcentaje equivalente al 68,9\% (Ministerio de Desarrollo Social, 2016, pp. 82-83).

Los datos proporcionados en los párrafos anteriores dan cuenta de que los principales flujos migratorios en Chile son de origen intrarregional y con fines económicos, vale decir, corrientes migratorias provenientes de países vecinos y en búsqueda de un trabajo o alguna ocupación para generar ingresos. Es por esto que el escenario migratorio en Chile responde de forma explícita al predominio de un tipo de migración: la migración económica, para la cual "la finalidad es trabajar (como asalariado o por cuenta ajena, como profesional independiente, como comerciante o en otro negocio propio) y obtener unos determinados ingresos económicos" (Giménez, 2003, pp. 24-25).

No obstante lo anterior, a pesar de que el principal motivo de migrar a Chile por parte de la población migrante sea una cuestión mayoritariamente económica-laboral, es imprescindible mencionar que existen muchas brechas y dificultades en lo que respecta a los procesos de incorporación laboral de estos mismos.

Según un estudio realizado por la consultora Ecléctica en un estudio de caracterización socio laboral del trabajador migrante en la Región Metropolitana, la instalación socio-laboral, y migratoria en general, es visualizada como un proceso lento y progresivo, además poco transparente de acceso a la información (Ecléctica Consultores, 2016, p. 22 ). De la misma manera, de acuerdo a datos entregados por un estudio realizado por la Organización Internacional para las Migraciones (OIM) en torno a la incorporación laboral de los migrantes en la Región Metropolitana, la falta de información y la ausencia de protocolos dirigidos a los empleadores que contengan los requisitos y procedimientos para contratar trabajadores migrantes, además de la insuficiente información que recibe el trabajador migrante, se ha identificado como una dificultad para la incorporación laboral en condiciones de regularidad (OIM, 2012, p. 39). 
Como consecuencia de lo anterior, la falta de canales de información y protocolos tanto para el mundo empresarial como para los propios trabajadores migrantes, en relación con cómo llevar a cabo los procesos formales de contratación laboral, es una situación que acarrea un problema importante de observar, puesto que fomenta la irregularidad administrativa en el caso de las personas migrantes. La irregularidad administrativa, - es decir, la ausencia de un estatus migratorio definido para trabajadores extranjeros - ר es mencionada como una de las condiciones que pone en más riesgo los derechos de los migrantes y como uno de los factores principales que incidirían negativamente en la adecuada incorporación de los migrantes en el mercado laboral formal (OIM, 2012, p. 36), y esta irregularidad se genera en gran parte en Chile producto de que la mayoría de los migrantes que ingresan al país de forma regular lo hace con visa de turista. Sin embargo, una parte de ellos pierde dicho estatus de regularidad cuando no logran obtener un contrato laboral que les permite optar a una visa de trabajo (OIM, 2012, p. 36), generándose así un mayor nivel de vulnerabilidad en las personas migrantes, que en lo concreto se traduce al desarrollo de trabajos informales, la dificultad de poder acceder a bienes y servicios públicos, así como también a la dificultad de ingresar formalmente a un trabajo producto de esta irregularidad.

Es bajo este escenario en donde se sitúa el presente artículo, planteando las siguientes interrogantes, las cuales operarán como hilo conductor para el desarrollo del texto: ¿Cuán informado está el mundo empresarial chileno respecto a los procesos de incorporación laboral de migrantes? ¿Cuánto maneja el mundo empresarial en Chile los marcos legislativos que podrían favorecer la incorporación laboral de migrantes? ¿Qué otros elementos más allá de la falta de información podrían estar obstaculizando la incorporación laboral migrante en el actual escenario social? ¿De qué manera la disciplina del Trabajo Social podría aportar para el fomento de la incorporación laboral migrante?

Sin lugar a dudas, las preguntas ya planteadas se presentan como una problemática imprescindible de abordar a través del presente artículo, considerando que el acceso al trabajo formal en la persona migrante es uno de los puntos de mayor importancia en relación con su calidad de vida, puesto que esto le da la oportunidad de generar ingresos a la persona, pero además de poder mantener su situación regular administrativa en el país.

\section{Marco referencial: contexto y conceptualizaciones}

Este artículo busca develar una serie de mitos asociados con los procesos de incorporación laboral migrante, los cuales dificultan que las personas extranjeras que residen en Chile puedan ejercer en plenitud su derecho al trabajo. De esta manera, se espera que el presente marco referencial pueda entregar ciertas luces para entender en mayor profundidad el desarrollo de los argumentos centrales del artículo.

En primer lugar, para efectos del presente artículo, el concepto de "mito" debe ser entendido como una construcción sin fundamento racional alguno, pensamientos imaginarios, alegórico, creencias infundadas que operan emocionalmente en los sujetos (Gil del Pino, 2005, p. 128).

En segundo lugar, por incorporación laboral se entenderá el acceso al empleo en condiciones laborales similares a la de los trabajadores nacionales, en el mismo sector o puesto de trabajo (OIM, 2012, p. 14). La definición expuesta responde a su vez a dos marcos legales de carácter nacional e internacional que aplican actualmente en Chile, los cuales de forma imprescindible se deben considerar en el presente artículo:

a. Convención Internacional sobre la protección de los derechos de todos los trabajadores migratorios y de sus familiares: Convención suscrita por Chile el 24 de septiembre de 1993 y que entró en vigor el $1^{\circ}$ de julio de 2005 . Dicha convención posee como objetivo central que los Estados Partes deben garantizar la protección internacional de los derechos de los trabajadores migrantes durante todo el proceso de migración, en conjunto además con sus familiares, sin distinción alguna por motivos de sexo, raza, color, idioma, religión o convicción, opinión política o de otra índole, origen nacional, étnico o social, nacionalidad, edad, situación económica, patrimonio, estado civil, nacimiento o cualquier otra condición. Asimismo, dicha protección será aplicable durante todo el proceso de migración de los trabajadores migratorios y sus familiares, que comprende la preparación para la migración, la partida, el tránsito y todo el periodo de estancia y de ejercicio de una actividad remunerada en el Estado de empleo, así como el regreso al Estado de origen o al Estado de residencia habitual.

b. Ley 20.609 (Establece medidas contra la discriminación): Ley promulgada el 12 de julio de 2012 y que entró en vigencia el 24 de julio 
del mismo año. Dicha ley posee como objetivo fundamental instaurar un mecanismo judicial que permita restablecer eficazmente el imperio del derecho toda vez que se comete un acto de discriminación arbitraria. Además corresponderá a cada uno de los órganos de la administración del Estado garantizar a toda persona el goce y el ejercicio legítimo de sus derechos y libertades reconocidas por la Constitución Política de la República, las leyes y tratados internacionales y ratificados por Chile y que se encuentren vigentes, en particular cuando esta vulneración al derecho se funden en motivos tales como la raza o etnia, nacionalidad, la situación socio-económica, el idioma, la ideología u opinión política, la religión o creencia, la sindicación o participación en organizaciones gremiales o la falta de ella, el sexo, la orientación sexual, la identidad de género, el estado civil, la edad, la filiación, la apariencia personal y la enfermedad o discapacidad.

Se torna sumamente relevante resaltar la presencia de estos dos marcos legales de carácter internacional como nacional suscritos y vigentes en Chile, los cuales dan cuenta de que la nacionalidad o la condición de migrante no es un impedimento para la incorporación laboral y que además el Estado debe garantizar el goce y el ejercicio pleno de este derecho. Por último, el presente artículo se fundamentará en dos marcos legales de importancia y con directa relación con la temática de migración y trabajo, que además de entregar información para comprender cómo se deben desarrollar los procesos de incorporación laboral en personas migrantes en Chile, proporcionarán antecedentes que permitan derribar los principales mitos que el artículo expondrá:

a. Decreto Ley 1.094 (Establece norma sobre extranjeros en Chile): Ley que regula la temática migratoria a nivel nacional, la cual fue dictada por el general Pinochet en el año 1975, durante la dictadura militar chilena, y es conocida como la Ley de Extranjería. Esta norma es reglamentada por el Decreto Supremo 597 de 1984, y posteriormente en el año 1996 fue modificada por la Ley 19.476, que introduce cambios en materia de refugio. Dichas normas rigen el ingreso al país, la residencia, las normas para trabajar, la permanencia definitiva, el egreso, el reingreso, la expulsión y el control de los extranjeros (Martínez, Soffia, Cubides y Bortolotto, 2013, p. 163).

b) Código del Trabajo: Código que regula las relaciones laborales entre los empleadores y los trabajadores en Chile.

Estos dos últimos marcos legales son imprescindibles de contemplar y analizar para la propuesta principal del presente artículo, considerando que la temática de migración y trabajo en Chile se regula mayoritariamente a partir de estos cuerpos legales ${ }^{1}$. Lo anterior puede además respaldarse por lo establecido por el mismo Decreto Supremo 597 (Reglamento de Extranjería), el cual en su artículo 36 letra f establece que, para el otorgamiento de la visa de trabajo para los extranjeros el proceso de contratación laboral y el contrato deben ajustarse a las disposiciones generales de orden laboral y previsional que sean atinentes.

\section{Método}

El presente artículo toma como unidades de análisis diferentes casos experimentados por medio del Programa de Interculturalidad de la Municipalidad de la Reina ${ }^{2}$, en relación con los esfuerzos que este mismo programa ha realizado para vincularse con las empresas o empleadores tanto dentro como fuera de la comuna previamente mencionada, con la finalidad de promover la incorporación laboral migrante.

Para explicar de mejor manera cómo nacieron estos casos analizados en el presente artículo es que se hace necesario mencionar que el programa de Interculturalidad de la Municipalidad de La Reina, dentro de las atenciones sociales diarias que desarrolla para la comunidad migrante del sector, pudo identificar que uno de los mayores desafíos que los extranjero enfrentan hoy en día es el hecho de ser aceptado en un trabajo formal con condiciones formales. En este contexto, dicho programa elaboró un taller denominado Taller de sensibilización y capacitación para la contratación laboral migrante dirigido a empresas tanto fuera como dentro de la comuna mencionada, con el objeto de entregar información sobre el desarrollo del fenómeno de la migración en Chile, capacitar a estas mismas en materia de contratación laboral migrante, sensibilizar a estas mismas

1 Se hace el alcance de "mayoritariamente" porque, según el artículo 1 del Código del Trabajo, las normas de este código no se aplicarán a los funcionarios de la Administración del Estado, centralizada y descentralizada, del Congreso Nacional y del Poder Judicial, ni a los trabajadores de las empresas o instituciones del Estado o de aquellas en que éste tenga aportes, participación o representación, siempre que dichos funcionarios o trabajadores se encuentren sometidos por ley a un estatuto especial.

2 Programa que contempla el trabajo en pos de la inclusión social de la comunidad migrante residente en dicha comuna. 
dándoles a entender cuáles son los efectos positivos que se genera en la vida del migrante al formalizar la relación laboral (preservar la regularidad migratoria administrativa, por dar un ejemplo),pero también con la finalidad de dialogar e indagar cuáles eran los conocimientos e ideas que las empresas tenían en relación con el tema en cuestión.

Este Taller de Sensibilización y Capacitación para la Contratación Laboral Migrante se empezó a desarrollar con el apoyo de la Oficina Municipal de Información Laboral (OMIL) de la respectiva municipalidad, la cual formalmente posee los vínculos con las diferentes empresas para efectos de la incorporación laboral.

Los principales hallazgos encontrados a partir del desarrollo del taller en cuestión es que muchas de las empresas o empleadores no sólo no contratan personal extranjero por falta de información o por desconocimiento con relación al tema, sino porque además muchas de éstas ya poseen ciertos criterios de selección de personal basados en ciertos mitos fruto de este desconocimiento, los cuales excluyen a las personas migrantes sobre la posibilidad de poder ejercer su derecho al trabajo.

En síntesis, el presente artículo es una aproximación empírica-interpretativa, la cual a su vez fue articulada con literatura pertinente en el tema que ha permitido llegar a conclusiones preliminares con el fin de poder fomentar la incorporación laboral migrante, la inclusión social y el mejor manejo de la información por parte del mundo empresarial chileno.

\section{Análisis: Mitos}

Como se mencionó en los párrafos anteriores, a partir del trabajo desarrollado por el Programa de Interculturalidad de la Municipalidad de La Reina (programa que contempla el trabajo en pos de la inclusión social de la comunidad migrante residente en la comuna ya mencionada) ha sido posible identificar una serie de mitos que dificultan los procesos de incorporación laboral migrante, fundamentados muchas veces por el desconocimiento que hay en torno al tema en cuestión.

A partir de lo anterior, se develan los principales mitos que muchas de las empresas utilizan a modo de argumento para no contratar personal extranjero, esto acompañado con sus respectivos argumentos para derribar estos mismos con la finalidad de contribuir al fomento de la incorporación laboral migrante, al mayor manejo de la información por parte del mundo empresarial en Chile, así como también de la comunidad migrante residente en el país.

\section{Mito $\mathrm{N}^{\circ} 1$}

"No contratamos extranjeros, ya que es necesario que el extranjero posea Cédula de Identidad chilena (RUT), para poder hacerles un contrato de trabajo"

La cédula de identidad chilena (RUT) es sin lugar a dudas uno de los mayores impedimentos existentes referente a los procesos de búsqueda y contratación laboral en las personas migrantes en Chile, especialmente en aquellos extranjeros en calidad de turistas, quienes son lo que recientemente han llegado al país y además no poseen la facultad de desarrollar actividades remuneradas acorde a lo establecido por el artículo 87 del Decreto Supremo 597 (Reglamento de Extranjería).

El ingreso de la población extranjera en calidad de turista al país es el camino más recurrente que estos desarrollan con la finalidad de poder tramitar un permiso de residencia y así poder trabajar formalmente en Chile. Según datos entregados por el Departamento de Extranjería y Migración, "la migración reciente (la cual está caracterizada por aquellas personas que ingresan al país con beneficio de turismo y luego solicitan visa por primera vez) al año 2016 aumentó un 51,4\% con relación al año 2015, lo que se refleja en la cantidad de solicitudes de visas del año 2016, equivalentes a 165.656 visas" (Silva y Ballesteros, 2017, p. 21).

No obstante lo anterior, para que esta población pueda obtener su respectivo permiso de residencia y trabajar formalmente en Chile, debe acogerse a una serie de requisitos, los cuales podrían variar de acuerdo a la realidad de cada persona (por motivos laborales, tratados internacionales, vínculo con chileno, vínculo con familiar que posea permanencia definitiva, por dar algunos ejemplos). En este contexto, el Departamento de Extranjería y Migración, en su Reporte Migratorio del año 2017, alude a que "en cuanto a las razones para solicitar visa, las personas en los últimos años han pedido principalmente visas de empleo, casi en un 70\% de los casos (Silva y Ballesteros, 2017, pp. 29)", situación que da cuenta de que mayoritariamente la población migrante que ingresa a Chile en calidad de turista busca, encuentra y envía al Departamento de Extranjería y Migración un contrato de trabajo para efectos de poder tramitar su respectivo permiso de residencia (RUT).

La pregunta que surge inmediatamente a raíz de los datos entregados previamente es ¿cómo poder formalizar una relación laboral mediante un contrato de trabajo a un extranjero en calidad de turista, quien no está facultado para trabajar y además no posee Cédula de Identidad chilena (RUT)? 
Para responder esta pregunta, es necesario aclarar previamente algunos artículos correspondientes al Decreto Supremo 597 (Reglamento de Extranjería). Dicho reglamento en su artículo 35 establece que se podrá otorgar visación de trabajo a los extranjeros que se encuentren en el territorio nacional y que tengan el propósito de radicarse en el país con el mismo fin. Asimismo, dicho decreto en su artículo 36 letra $\mathrm{f}$ establece que para el otorgamiento de la visación de trabajo correspondiente, la contratación y el contrato deben ajustarse a las disposiciones generales de orden laboral y previsional que sean atinentes. En otras palabras, la ley faculta a que las personas migrantes que se encuentren en calidad de turistas en el territorio nacional puedan dar cumplimiento a un contrato de trabajo, y como consecuencia de ello cambiar su estatus migratorio, pedir residencia y poder trabajar formalmente en Chile.

Para efectos de lo anterior, el contrato de trabajo y la contratación deben ajustarse a las disposiciones generales de orden laboral y previsional, es decir, a los mínimos planteados por el Código del Trabajo en Chile. Así, si se analiza exhaustivamente el Título I del Código del Trabajo (título que refiere específicamente al contrato individual de trabajo), específicamente en su artículo 10, es posible concluir que no es necesaria la existencia de un RUT para efectos de celebrar un Contrato de Trabajo. Este artículo alude a que el contrato de trabajo debe contener, a lo menos, las siguientes estipulaciones:

\section{Lugar y fecha del contrato}

2. Individualización de las partes con indicación de la nacionalidad y fechas de nacimiento e ingreso del trabajador.

3. Determinación de la naturaleza de los servicios y del lugar o ciudad en que hayan de prestarse.

4. Monto, forma y periodo de pago de la remuneración acordada.

5. Duración y distribución de la jornada de trabajo.

6. Plazo del contrato.

7. Demás pactos que acordarán las partes (bonos, beneficios adicionales, etc.) (Ministerio del Trabajo y Previsión Social, 2017, p. 9).

En síntesis, el Código del Trabajo no estipula la necesidad de un RUT para efectos de poder celebrar un contrato de trabajo. En este sentido, con aquellas personas extranjeras que no posean Cédula de Identidad chilena (RUT), con el $\mathrm{N}^{\circ}$ de Pasaporte de la persona extranjera más un contrato de trabajo puede celebrarse una relación laboral sin ningún inconveniente legal.
Las aclaraciones previamente descritas son imprescindibles de manejar, difundir y efectuar en vías de poder garantizar un real goce y ejercicio pleno del derecho al acceso al trabajo en igualdad de condiciones de todas las personas migrantes que llegan a Chile. Lo anterior se torna aún más sustancial entendiendo que garantizar el acceso al trabajo en igualdad de condiciones para las personas migrantes es una responsabilidad y un deber que el Estado de Chile posee a través de su adhesión a la Convención Internacional sobre la Protección de los Derechos de todos los trabajadores migratorios y de sus familiares, la cual establece en su artículo 25 que los trabajadores migratorios gozarán de un trato que no sea menos favorable que el que reciben los nacionales del Estado de empleo en lo tocante a remuneración y de otras condiciones de trabajo y de empleo.

\section{Mito $\mathrm{N}^{\circ} 2$}

\section{"No contratamos extranjeros porque tenemos que pagar los pasajes de retorno a su país si se termina la relación laboral"}

Adicional a toda la información proporcionada en la explicación del Mito 1, para efectos de poder formalizar una relación laboral con personas migrantes en Chile sin ningún inconveniente legal, el Decreto Supremo 597 además plantea en su artículo 37 la obligación de contemplar "una clausula especial en el contrato en virtud de la cual el empleador o patrón se compromete a pagar al trabajador y demás miembros de su familia que se estipulen, el pasaje de regreso a su país de origen o al que se convenga. Podrá exigirse, además, la garantía que se estime conveniente para asegurar dicho pago".

Desde el funcionamiento de la actual Ley de Migración (Decreto Ley 1.094) con su respectivo Reglamento (Decreto Supremo 597), la principal visa existente para efectos laborales ha sido la Visa Sujeta a Contrato, la cual dentro de sus particularidades exige que el contrato de trabajo que se celebre para contratar a una persona extranjera contemple lo estipulado en el párrafo anterior (cláusula de viaje), contemple además la posibilidad de que la persona extranjera pueda trabajar única y exclusivamente con la persona con quien se suscribió el contrato y la finalización de la visa desde el momento en que se pone término a la relación contractual por cualquiera de las partes.

A raíz de lo anterior, y considerando la rigurosidad que posee la Visa Sujeta a Contrato para efectos de la contratación laboral, a partir de marzo del año 2015, el Departamento de Extranjería y Migración 
puso en funcionamiento la nueva Visa Temporaria por Motivos Laborales, quedando así a libre elección de la persona extranjera la postulación a esta misma o a la Visa Sujeta a contrato.

Una de las grandes y principales modificaciones que trajo la Visa Temporaria por Motivos Laborales es que el contrato de trabajo no debe contener cláusula de viaje, es decir, no obliga al empleador a cancelar los pasajes de retorno al trabajador extranjero, en caso de quiebre de la relación laboral.

Otra gran modificación que trajo la Visa Temporaria por Motivos Laborales, a diferencia de la Visa Sujeta a Contrato, es que el empleador no está obligado a informar el fin de la relación laboral en caso de quiebre de esta misma. Además, aquellos extranjeros que posean Visa Temporaria por Motivos Laborales podrán trabajar con los empleadores que gusten durante la duración de esta misma, y 90 días antes del término de esta visa, si es que poseen los mínimos establecidos por el Departamento de Extranjería y Migración, podrán postular a su Permanencia Definitiva.

A partir de la información entregada, se torna relevante enfatizar el hecho de que aún a la fecha existan ciertas empresas que no contraten personal extranjero para así evitar la cláusula de viaje. Lo anterior refiere a una falta de actualización y manejo de información en la materia en cuestión por parte del mundo empresarial, que termina excluyendo y vulnerando un derecho esencial a las personas extranjeras que residen en Chile: el derecho al acceso al trabajo.

\section{Mito $\mathrm{N}^{\circ} 3$}

\section{"No contratamos extranjeros, mucho papeleo"}

Si se observa detenidamente la información entregada en los dos mitos previamente planteados, contratar a una persona extranjera que no posea Cédula de Identidad chilena (RUT) no es un proceso de alta complejidad. Si se analizan los requisitos que el Departamento de Extranjería y Migración demanda para efectos de tramitar la Visa Temporaria por Motivos Laborales, es posible encontrar que el empleador el único documento con el cual debe contribuir para efectos de comenzar la tramitación de la visa es el contrato de trabajo, el cual además de contener todos los mínimos establecidos en el artículo 10 del Código del Trabajo, debe contener las siguientes cláusulas:

- Remuneración: Debe ser igual o superior al sueldo mínimo, acorde con el cargo o actividad a desarrollar en el país y según las normas laborales vigentes.
- Cláusula de Vigencia: Esta cláusula alude a que "la obligación de prestar servicios emanada del presente contrato sólo podrá cumplirse una vez que el (la) trabajador(a) haya obtenido la visación de residencia correspondiente en Chile o el permiso especial de trabajo para extranjeros con visa en trámite.

- Cláusula Previsional: Esta cláusula alude a que el (la) trabajador(a) cotizará en el régimen previsional chileno, comprometiéndose el empleador a efectuarse las retenciones y entregarlas a las instituciones correspondientes.

- Cláusula de Impuesto a la Renta (sólo en los casos de sueldos superiores a 13,5 UTM): Esta cláusula alude a que el (la) empleador(a) tiene la obligación de responder al pago de impuesto a la renta correspondiente en relación con la remuneración pagada.

Los demás documentos solicitados para efectos de tramitar la Visa Temporaria por Motivos Laborales son de única responsabilidad del trabajador, es decir, de la persona migrante y no de responsabilidad del empleador. Estos documentos son:

- Solicitud de Visa Temporaria vía correo llenada íntegramente y firmada.

- 1 fotocopia del pasaporte (hoja de identificación, número y fechas de otorgamiento y vencimiento de éste y hoja con timbre de ingreso, además, cuando corresponda, fotocopia del Visto de Turismo). En caso de ingreso al país con otro documento de identificación, adjuntar 1 fotocopia de la cédula de identidad, DNI, etc.

- 1 fotocopia de la última Tarjeta de Turismo.

- 1 fotografía reciente, tamaño carné (3x2 cm), en colores, con nombre completo y número de pasaporte.

- Documentación específica obligatoria: Los nacionales de Colombia deben presentar además un Certificado de Antecedentes Judiciales vigente y totalmente tramitado. Los nacionales de Perú deben presentar un Certificado Consular de Antecedentes Penales vigente solicitado en su consulado. Los nacionales de República Dominicana deberán presentar el certificado de No Antecedentes Penales vigente, obtenido en el consulado de República Dominicana en Chile.

Por otro lado, en relación con el mito en cuestión, cabe destacar además que si la persona extranjera ya posee su Cédula de Identidad (Temporaria o Definitiva) se le puede realizar un contrato de trabajo como a cualquier chileno más, entendiendo que los 
extranjeros que se encuentran en dicha situación pueden realizar cualquier actividad lícita en el país. Es de suma relevancia destacar que en aquellos casos en los cuales la persona extranjera no posea su Tarjeta Especial de Trabajo para Extranjero con Residencia en Trámite, ni su cédula de identidad chilena (RUT) y necesite tramitar su Visa Temporaria por Motivos Laborales por primera vez, la responsabilidad de reunir toda la documentación general para efectos de dicho trámite es única y exclusivamente de la persona extranjera. El único documento con el cual la empresa/empleador debe aportar es con el contrato de trabajo.

Lo expuesto en el párrafo anterior es de suma importancia considerando que actualmente existen muchas empresas/empleadores que asocian inmediatamente la incorporación laboral migrante con trámite o papeleo. En este sentido, es sustancial dar a entender que los procesos de contratación laboral son exactamente los mismos entre una persona nacional y una persona extranjera, es decir escriturar el contrato de trabajo es obligación para ambos casos, la única diferencia es que en ciertos casos la persona extranjera debe iniciar un proceso administrativo con este mismo contrato con la finalidad de obtener su visa de trabajo correspondiente ${ }^{3}$.

\section{Mito $\mathrm{N}^{\circ} 4$}

\section{"No contratamos extranjeros, se demora mucho el trámite"}

El proceso administrativo que la persona migrante muchas veces debe realizar para efectos de poder obtener su visa de trabajo efectivamente es un proceso engorroso. Sin embargo, el Departamento de Extranjería y Migración entrega un par de opciones para que la persona pueda trabajar sin ningún problema y paralelamente esperar que la tramitación de su visa concluya, como por ejemplo pedir un Permiso de Trabajo.

El Departamento de Extranjería y Migración (DEM), dentro de sus competencias, está facultado para poder emitir dos tipos de permisos de trabajo:

1. Tarjeta Especial de Trabajo para Turista Extranjero: Este permiso, según lo establecido en el artículo 100 del Decreto Supremo 597, se tramita de forma inmediata en el Departamento de Extranjería y Migración (DEM) y faculta a su titular a poder trabajar sin ningún problema con la persona con quien se suscribió el contrato de trabajo. Este posee una duración de 30 días, prorrogables hasta el vencimiento de la visa de turista de la persona extranjera.

2. Tarjeta Especial de Trabajo para Extranjero con Residencia en Trámite: Este permiso se obtiene una vez que es aceptada la visa de la persona extranjera y faculta a su titular a poder trabajar con todos empleadores que el extranjero estime conveniente. Este se entiende que dura hasta el otorgamiento (estampado) de la visa correspondiente.

Uno de los hallazgos que más llamó la atención, con relación al desarrollo del Taller de Sensibilización y Capacitación para la contratación laboral migrante que ejecuta el Programa de Interculturalidad de la Municipalidad de La Reina, fue el desconocimiento en profundidad que existían en las respectivas empresas sobre la existencia de estos permisos de trabajo. Lo anterior vuelve a poner en evidencia el desconocimiento que estas mismas poseen sobre los procesos de incorporación laboral migrante, situación que sin lugar a dudas hay que revertir en aras de que los trabajadores migrantes en Chile no sean privados de su derecho de poder trabajar.

Resulta interesante poner en tensión el hecho de que ciertas empresas no acepten incorporar trabajadores migrantes por un tema de tiempo, con los principios de la Ley 20.609 (Establece medidas contra la discriminación), cuerpo legal vigente en Chile desde el año 2012, el cual establece que es responsabilidad del Estado de Chile implementar medidas para garantizar el goce y el ejercicio pleno de los derechos de todas las personas sin importar su condición ni situación. Desde el enfoque de este cuerpo legal, resulta sumamente discriminatorio excluir a una persona migrante sobre la posibilidad de poder trabajar por un motivo que básicamente no depende de ellos; como el tiempo que demora el Departamento de Extranjería y Migración (DEM) en resolver los respectivos permisos de residencia. En este escenario, es imprescindible desarrollar una promoción y difusión exhaustiva de las diferentes alternativas existentes para que las personas extranjeras puedan trabajar en Chile, de manera que el tiempo, la situación migratoria de la persona o cualquier otra variable no obstaculice ni prive el acceso al trabajo.

3 Esta situación se plantea única y exclusivamente en aquellos extranjeros en calidad de turistas, es decir, aquellas personas que recién han llegado al país, que no poseen ni permiso de trabajo ni Cédula de Identidad chilena. En aquellos casos de extranjeros que posean Cédula de Identidad chilena, ya sea Temporaria o Definitiva, se les puede contratar como a cualquier persona chilena más. 


\section{Mito $N^{\circ} 5$}

\section{"Contratamos sólo extranjeros que posean Perma- nencia Definitiva"}

Muchas de las empresas que deciden contratar personas extranjeras, dentro de sus requisitos para hacerlo manifiestan que éste debe tener Permanencia Definitiva, dejando de lado a aquellas personas que no poseen Cédula de Identidad chilena o que poseen Visa Temporaria.

Frente a esta situación se torna imprescindible analizar el Decreto Supremo 597, Reglamento de Extranjería vigente en Chile, con la finalidad de evidenciar si es que existe alguna diferencia en términos laborales entre la Permanencia Definitiva y la Visa Temporaria.

Según lo establecido en el artículo 80 del Decreto Supremo 597, "la permanencia definitiva es el permiso concedido a los extranjeros para radicarse indefinidamente en el país y desarrollar cualesquiera clase de actividades, sin otras limitaciones que las que establezcan las disposiciones legales y reglamentarias".

Por otro lado, acorde al artículo 49 y 52 del Decreto Supremo 597, la visa temporaria "se otorgará al extranjero que tenga el propósito de radicarse en Chile, siempre que acredite tener vínculos de familia o intereses en el país o cuya residencia sea estimada útil o ventajosa (...) los titulares de esta visación podrán desarrollar cualesquiera clase de actividad lícita en el país (...) tendrá una vigencia máxima de un año y podrá prorrogarse sólo una vez por igual periodo".

A partir de lo establecido en los artículos 49, 52 y 80 del Decreto Supremo 597 (Reglamento de Extranjería), la Permanencia Definitiva y la Visa Temporaria, en términos laborales, facultan a su titular a realizar las mismas actividades lícitas en el país (incluido trabajar). No es que una otorgue mayores derechos que la otra. Lo único que cambia es la duración de los permisos.

El criterio de contratar sólo personas que poseen Permanencia Definitiva, por sobre las personas que poseen sólo visa temporaria o visa de turismo, es sin lugar a dudas un acto de discriminación el cual hay que revertir como dé lugar. Dicha decisión por parte de ciertas empresas evidencia una exclusión hacia las personas migrantes sobre su derecho de poder acceder al trabajo en Chile, sólo fundamentado en el hecho de no contar con los documentos demandados por la empresa, situación que se torna aún más grave considerando que hoy en día existen todas las opciones administrativas para asegurar el acceso al trabajo en las personas migrantes sin importar su situación migratoria.

Es sumamente importante observar esta situación a la luz de lo planteado por la Convención Internacional sobre la protección de los derechos de todos los trabajadores migratorios y de sus familiares, marco legal internacional vigente en Chile, el cual establece en su artículo 25 que los trabajadores migratorios gozarán de un trato que no sea menos favorable que el que reciben los nacionales del Estado de empleo en lo tocante a remuneración y de otras condiciones de trabajo o de empleo. Asimismo dicho artículo, en su párrafo 3, establece que los Estados Partes adoptarán todas las medidas adecuadas para asegurar que los trabajadores migratorios no sean privados de ninguno de los derechos derivados de este principio a causa de irregularidades en su permanencia o empleo, principio que evidentemente no se respeta ni se da cumplimiento por el hecho de que ciertas empresas/empleadores priorizan a ciertos trabajadores por sobre otros basados en el tipo de residencia que la persona migrante posee.

\section{Mito $\mathrm{N}^{\circ} 6$}

\section{"No contratamos extranjeros, ya que vienen los menos preparados"}

Otro de los hallazgos encontrados a partir del trabajo de vinculación que desarrolló el Programa de Interculturalidad de la Municipalidad de La Reina con ciertas empresas es que muchas de estas observan a las personas migrantes como "no preparadas" para el desarrollo de ciertos cargos laborales basándose en el nivel educacional que estos poseen.

Lo anterior resulta sumamente importante de analizar en mayor profundidad, puesto que si la preparación para el desarrollo de ciertos cargos laborales dependiera del nivel educacional, los migrantes estarían mucho más preparados que los propios chilenos, considerando los datos entregados por la Encuesta de Caracterización Socioeconómica Nacional (CASEN-Inmigrantes 2015), en donde los extranjeros residentes en Chile poseen 12,6 años promedio de escolaridad, a diferencia de la población chilena que posee 11,0 años promedio de escolaridad.

Asimismo, si se observan más detenidamente los datos otorgados por la Encuesta CASEN- Inmigrantes 2015 en relación con los promedios de años de estudio de la comunidad migrante residente en Chile, es posible determinar incluso que los países con mayor presencia en el país (tales como Perú, Argentina, Colombia, Bolivia, Ecuador) poseen mayores años promedio de escolaridad que las personas na- 
cidas en Chile, con excepción de Bolivia (Ministerio de Desarrollo Social, 2016, p. 59).

De esta manera, el promedio de años de estudio de los nacionales peruanos residentes en Chile alcanza los 12,2 años, en el caso de los nacionales de Argentina equivale a los 12,3 años, 12,3 años también en el caso de los nacionales de Colombia, 10,6 años de estudio acorde a los nacionales de Bolivia y 12,0 años promedio de estudio en el caso de los nacionales del Ecuador (Ministerio de Desarrollo Social, 2016, p. 59).

A partir de los datos entregados en los párrafos anteriores, es posible determinar que las percepciones por parte de ciertas empresas en torno a la preparación laboral de los migrantes es errada si se consideran los años promedio de escolaridad de estos mismos, los cuales son incluso superiores que los años promedio de escolaridad de los chilenos. "El capital cultural de los migrantes es probablemente superior al de los chilenos, y que por lo mismo los migrantes aportan, al menos potencialmente, más recursos y conocimiento al desarrollo de la sociedad chilena que los propios chilenos. Adicionalmente, podemos decir que si consideramos que la mayoría de los migrantes se ha formado en los sistemas educativos de sus países de procedencia, en términos estrictamente macroeconómicos, los países de origen están subvencionando a la sociedad chilena a través de sus sistemas educativos y de formación de recursos humanos. Dicho en otros términos, la descapitalización de los países de procedencia de los migrantes está siendo funcional al desarrollo económico de Chile. Esta sociedad les debe, a los migrantes al menos, el reconocimiento institucional y social de los años de estudio y el capital cultural que han acumulado a lo largo de sus vidas" (Thayer, 2016, pp. 80-81).

\section{Mito $\mathrm{N}^{\circ} 7$}

\section{"Contratamos sólo extranjeros que poseen Cédula de Identidad chilena (RUT), ya que sin RUT no podemos cancelar las cotizaciones previsionales correspondientes"}

En el trabajo de vinculación por parte del Programa de Interculturalidad de la Municipalidad de la Reina con las empresas/empleadores fuera y dentro de la comuna mencionada, se pudo rescatar una interrogante no menor de mencionar en el presente artículo.

Una de las mayores dudas que estos plantearon fue el cómo poder efectuar el íntegro pago de las cotizaciones previsionales sin la existencia de RUT, interrogante que incluso a muchas de estas empresas o empleadores les llevó a la simple determinación de no contratar personal extranjero por miedo a sanciones por el no cumplimiento de la ley. A partir de esta interrogante, es sustancial mencionar que efectivamente para efectos del íntegro pago de las cotizaciones previsionales se requiere de un RUT. No obstante lo anterior, en aquellos casos de trabajadores extranjeros que no posean aún su Cédula de Identidad chilena (RUT), es posible poder emitir un Rol provisorio para efectos del pago de las cotizaciones previsionales.

Para efectos de lo anterior, el trabajador extranjero debe enviar a la Administradora de Fondo de Pensiones (AFP) que posee la actual licitación para administrar la cartera de nuevos afiliados (AFP Plan-Vital hasta el 31 de julio de 2018) los siguientes documentos:

- Copia notariada de Contrato de Trabajo.

- Fotocopia pasaporte.

- Declaración simple, indicando fecha inicio de labores.

De esta manera, el empleador podrá pagar las respectivas cotizaciones previsionales al Rol provisorio entregado por la respectiva AFP Plan-Vital, mientras paralelamente se resuelve la tramitación de la respectiva visa. Así, una vez que el trabajador extranjero posea su Cédula de Identidad chilena, y por consiguiente su RUT chileno, éste debe volver a la AFP Plan-Vital para hacer el traspaso de los fondos correspondientes a su RUT chileno.

Resulta relevante resaltar nuevamente, cómo el no manejo de la información o de los protocolos asociados a la contratación laboral migrante por parte de ciertas empresas o empleadores, termina privando a ciertos trabajadores extranjeros de su derecho de poder acceder a un trabajo formal, especialmente en aquellos que están en calidad de turistas, quienes son lo que no poseen un RUT y además son lo que recién han llegado al país y por consiguiente requieren de un mayor apoyo para poder comenzar su nuevo proyecto de vida en Chile.

Asimismo, resulta relevante poner en tensión el presente mito con el mito $N^{\circ} 1$, en donde la Cédula de Identidad chilena (RUT) pareciera ser el documento necesario para garantizar el acceso al trabajo con todas las formalidades correspondientes (como el pago íntegro de las cotizaciones por dar un ejemplo). Esta situación se torna aún más compleja considerando que hoy en día existen los marcos legales y los protocolos administrativos que garantizan el acceso al trabajo sin importar la situación migratoria de la persona extranjera. 


\section{Otras consideraciones que podrian dificultar los procesos de incorporación laboral de las personas migrantes}

"No contratamos extranjeros porque ya tenemos contratados la cantidad máxima legal de extranjeros permitidos por ley"

Otro elemento que posee directa relación con la temática de incorporación laboral migrante, que no aplica dentro del marco de mito por la veracidad de este mismo, es lo establecido por el artículo 19 del Código del Trabajo ("De la nacionalidad de los Trabajadores") ${ }^{4}$.

De las empresas o empleadores con los cuales el Programa de Interculturalidad de la Municipalidad de la Reina tomó contacto, un gran número de éstas desconocían la existencia de un máximo legal permitido para contratar personal extranjero y la otra cantidad de éstas simplemente utilizaban dicho artículo como un argumento para no contratar personal extranjero.

En relación con lo planteado en los párrafos anteriores, se hace imprescindible analizar el Código del Trabajo en mayor detalle para comprender de forma integral el funcionamiento del máximo legal mencionado previamente.

Muchas empresas utilizan el artículo 19 del Código del Trabajo como fundamento para no contratar personal extranjero. No obstante lo anterior, muchas de estas empresas desconocen o simplemente prescinden del artículo 20 del Código del Trabajo, el cual estipula que "para computar la proporción a que se refiere el artículo 19 del Código del Trabajo, se seguirán las reglas que a continuación se expresan:

1. Se tomará en cuenta el número total de trabajadores que un empleador ocupe dentro del territorio nacional y no el de las distintas sucursales separadamente;

2. Se excluirá al personal técnico especialista;

3. Se tendrá como chileno al extranjero cuyo cónyuge o conviviente civil o sus hijos sean chilenos o que sea viudo o viuda de cónyuge chileno, y

4. Se considerará también como chilenos a los extranjeros residentes por más de cinco años en el país, sin tomarse en cuenta las ausencias accidentales".
A raíz de lo anterior, es posible mencionar que efectivamente existe un máximo legal (equivalente al 15\%) para poder contratar personal extranjero, en aquellas empresas que posean 25 o más trabajadores, pero también es sustancial que las empresas consideren lo establecido en el artículo 20 del Código del Trabajo y que de esta manera contengan información actualizada sobre la situación de vida de sus trabajadores migrantes, con la finalidad de ir evaluando el real stock de trabajadores no chilenos. Los extranjeros, a medida que va transcurriendo el tiempo, adquieren vínculos con chilenos (sus hijos nacen en el territorio nacional, por dar un ejemplo), van adquiriendo años de residencia en el país y también adquieren estudios técnico profesionales. En este sentido, que un trabajador extranjero quede marginado del 15\% establecido por el Código del Trabajo, es una situación muy probable que suceda.

\section{Reflexiones finales a partir del rol del Trabajo Social}

A partir de la información y los análisis entregados en el presente artículo, se presentan algunas reflexiones con la finalidad de contribuir al mayor manejo de información al mundo empresarial en Chile, así como también para contribuir a los procesos de incorporación socio laboral de la comunidad migrante residente en el país. Así también se plantean ciertas recomendaciones desde la disciplina del Trabajo Social, a modo de contribuir en el abordaje de la temática en cuestión:

- Desde la disciplina del Trabajo Social, es imprescindible que, para un real proceso de incorporación socio laboral de la comunidad migrante, se diseñen, gestionen y evalúen espacios de capacitación y sensibilización con el mundo empresarial en Chile. Estos espacios deben ir dirigidos al mundo empresarial basados en un enfoque de derechos humanos, con el objeto de identificar a las personas migrantes como sujeto de derechos por su condición humana, y no por su nacionalidad o situación migratoria.

- El derrumbamiento de todos los mitos asociados a la contratación laboral migrante es una acción que debe realizarse de forma coordinada e intersectorial, por medio del desarrollo de espacios de capacitación apoyados por actores de gobierno central, gobiernos locales y actores de la sociedad

4 El artículo 19 del Código del Trabajo alude a que el ochenta y cinco por ciento, a lo menos, de los trabajadores que sirvan a un mismo empleador será de nacionalidad chilena. Se exceptúa de esta disposición el empleador que no ocupa más de veinticinco trabajadores. 
civil como líderes migrantes que podrían aportar desde sus experiencias al respecto.

- Además de la realización de espacios de capacitación y sensibilización, es insoslayable generar toda una línea de difusión y promoción de derechos que complemente los espacios de capacitación. De esta manera, la entrega de dípticos informativos que entreguen información clara y concisa ayudará a reforzar los contenidos contemplados.

- Asimismo, se hace necesario la generación de espacios para empoderar a la comunidad migrante en torno al manejo de sus deberes y derechos laborales, los mitos asociados a los procesos de contratación laboral migrante, así como también de todos los marcos legales existentes que comprenden a las personas migrantes como sujetos de derecho.

- Desde el Trabajo Social, el fomento de la asociatividad migrante y el apoyo en la generación de líderes migrantes, se entiende como una buena estrategia de sensibilización e incidencia en la vinculación con el mundo empresarial. Muchos de los extranjeros que residen en Chile poseen la experiencia práctica de los procesos administrativos que debieron cursar antes de poder trabajar. De este modo, que aquellos extranjeros con mayor experiencia en el país puedan capacitar y enseñar a sus propios compatriotas es una estrategia de gran impacto para los procesos de inclusión socio laboral de la comunidad migrante.

- Es importante aprovechar los datos existentes sobre el fenómeno migratorio en Chile e instalar, fundamentado en estos mismos, percepciones o ideas positivas de cómo apreciar el fenómeno migratorio. Observar la migración como una oportunidad más que un problema es un buen primer paso para el fomento de la inclusión socio laboral de la comunidad migrante en el país. En este sentido, es imprescindible generar espacios de interculturalidad que promuevan el intercambio y la relación entre las distintas culturas que coexisten en un contexto determinado. La interculturalidad en este contexto debe ser entendida como "una comunicación comprensiva entre las distintas culturas que conviven en un mismo espacio, siendo a través de estas donde se produce el enriquecimiento mutuo y, por consiguiente, el reconocimiento y la valoración (tanto intrínseca como extrínseca) de cada una de las culturas en un marco de igualdad" (Hernández, 2005, p. 78).

\section{Conclusiones}

Para efectos de las conclusiones es que se responderán las preguntas directrices planteadas en la presentación del presente artículo, con la finalidad de dar cuenta de si el artículo es un aporte para la temática tratada. Así, la primera pregunta apunta a ¿cuán informado está el mundo empresarial chileno respecto a los procesos de incorporación laboral de migrantes?

El mundo empresarial en Chile demuestra en términos generales un desconocimiento respecto a los procesos o protocolos existentes en el país para la contratación e incorporación laboral en personas migrantes. Este desconocimiento genera efectos negativos en los proyectos de vida de todas las personas extranjeras que optan por vivir en Chile, en particular en las personas en calidad de turistas que no cuentan con una Cédula de Identidad de Chile que les permita acceder de forma más expedita a un trabajo formal.

Es imprescindible que el Estado de Chile realice un trabajo en profundidad con el mundo empresarial chileno, en vías de poder capacitar e informar sobre los procesos y protocolos para la contratación e incorporación laboral migrante, y así garantizar el acceso pleno al trabajo a las personas extranjeras sin importar su situación ni condición. Según datos entregados por la Encuesta de Caracterización Socioeconómica Nacional (CASEN-Inmigrantes 2015), un 69,6\% de los extranjeros residentes en Chile se desenvuelven en el sector privado (Ministerio de Desarrollo Social, 2016, pp. 78), situación que hace aún más urgente la necesidad de un trabajo en coordinación entre el Estado y el mundo empresarial chileno.

Por otro lado, la segunda pregunta refiere a ¿cuánto maneja el mundo empresarial en Chile los marcos legislativos que podrían favorecer la incorporación laboral de migrantes?

El desconocimiento existente por parte de las empresas en relación con el tema de migración e incorporación laboral también se refleja en la no familiarización con marcos legales de importancia en el tema, tales como la Convención Internacional sobre la Protección de todos los Trabajadores Migratorios y sus Familiares y la Ley de Extranjería (Decreto de Ley 1.094) con su respectivo reglamento (Decreto Supremo 597)

Dicho desconocimiento y desinformación genera incertidumbre en el mundo empresarial en Chile, situación que termina afectando directamente a la población extranjera, los cuales en ciertos casos se 
ven privados sobre la posibilidad de poder acceder a un trabajo formal, producto de no contar con un RUT o cualquier documento de exigencia de la empresa.

Ligado con lo anterior, se plantea la tercera pregunta, la cual apunta a ¿qué otros elementos más allá de la falta de información podrían estar obstaculizando la incorporación laboral migrante en el actual escenario social?

Como fruto de este desconocimiento y desinformación por parte de las empresas en los procesos de contratación laboral migrante, estas han generado una serie de mitos que son los que hoy en día operan como los principales obstaculizadores para la incorporación laboral de personas extranjeras. Dichos mitos impiden que los trabajadores migrantes puedan ejercer su derecho de acceso al trabajo, desembocando en muchas ocasiones en la migración irregular administrativa y por ende en el aumento de los niveles de vulnerabilidad de la población extranjera.

Estos mitos deben ser abordados y derribados a partir del desarrollo de diferentes espacios de capacitación, tales como: seminarios, capacitaciones, charlas informativas, etc. Sin embargo, esto debe ser además contemplado como una responsabilidad a nivel gubernamental con el objeto de impedir el trabajo informal, los abusos laborales y fomentar el mejor manejo de la información sobre los protocolos y procedimientos para una incorporación laboral migrante segura, formal y ordenada.

Finalmente, se presenta la última pregunta, la cual alude a ide qué manera la disciplina del Trabajo Social podría aportar para el fomento de la incorporación laboral migrante?

Bajo el contexto de intervención de los gobiernos locales, el trabajador social cumple un rol esencial para el fomento de la incorporación laboral migrante. En primera instancia, éste puede aportar en la elaboración diagnóstica de la realidad migratoria propia del contexto de intervención, de manera tal que se pueda identificar dónde radica específicamente el problema que obstaculiza la incorporación laboral migrante. En el contexto de la comuna de La Reina, se pudo identificar que los mitos operan como las principales barreras para el acceso formal al trabajo para los extranjeros; sin embargo, en otros contextos comunales pudiesen existir otras problemáticas asociadas al fenómeno de la migración que dificultan aún más esta incorporación, tales como: el tema idioma, la interculturalidad, el racismo, la xenofobia. En síntesis, la figura del trabajador social se torna insoslayable con el objeto de desarrollar planes de intervención situados en un contexto determinado, que responda a las problemáticas propias de la comuna.

Por último, en términos metodológicos el trabajador social puede aportar en el diseño, coordinación y ejecución de proyectos para la generación de espacios para capacitar y empoderar tanto a la comunidad migrante como a la comunidad de empleadores, sobre todo los derechos relacionados con la incorporación formal al trabajo -cotizaciones previsionales, seguridad social, seguro de accidentes del trabajo o enfermedades profesionales, seguro de cesantía, entre otros-. Lo anterior es de suma relevancia entendiendo que el acceso de los trabajadores migrantes al sistema de seguridad social promueve una migración segura y además preserva la regularidad administrativa de estos mismos, entendiendo que las cotizaciones previsionales son una de las principales fuentes para acreditar actividad e ingresos económicos en el país, lo que es de gran utilidad para la comunidad extranjera para efectos de la tramitación de los respectivos permisos de residencia.

\section{Referencias bibliográficas}

ECLÉCTICA CONSULTORES. (2016). Informe Integrado, investigación trayectorias laborales del trabajador migrante en la Región Metropolitana. Santiago-Chile. Abril 2016.

GIL DEL PINO, M. (2005). Convivir en la diversidad: Una propuesta de integración social desde la escuela. España. Editorial MAD, S.L.

GIMÉNEZ, C. (2003). Qué es la inmigración ¿Problema u oportunidad? ¿Cómo lograr la integración de los inmigrantes? ¿Multiculturalismo o interculturalidad? Barcelona: Integral.

HERNÁNDEZ, V. (2005). Cultura, multiculturalidad, interculturalidad y transculturalidad: Evolución de un término. IN MEMORIAM.

MARTÍNEZ, J; SOFFIA M; CUBIDES, D. Y BORTOLOTTO, I. (2013) Migración Internacional en Chile: Tendencias políticas, normas y participación de la sociedad civil. Santiago de Chile. Edición SIMN.

MELANO, M. Y DESLAURIERS, J. (2012). El trabajo social Latinoamericano. Elementos de identidad. Buenos Aires, Argentina. Grupo Editorial Lumen.

MINISTERIO DE DESARROLLO SOCIAL. (2016). CASEN 2015- Inmigrantes. Principales Resultados (versión extendida). 
OBSERVATORIO IBEROAMERICANO SOBRE MOVILIDAD HUMANA, MIGRACIONES Y DESARROLLO. (2016). La Migración en Chile: Breve Reportaje y Caracterización. Madrid, España. OBIMID Ediciones.

ORGANIZACIÓN INTERNACIONAL PARA LAS MIGRACIONES (OIM). (2012). Incorporación Laboral de los migrantes en la Región Metropolitana. Santiago de Chile.

SILVA, C. Y BALLESTEROS, V. (2017). Reportes Migratorios. Población Migrante en Chile. Santiago de Chile. Departamento de Extranjería y Migración, Ministerio del Interior y Seguridad Pública.

CORREA, L. (2016). Migración y derechos humanos: mediación social intercultural en el ámbito local. Santiago de Chile: Editorial LOM. 


\title{
Comentario sobre el artículo: Migración y trabajo en Chile. Derribando mitos asociados a los procesos de incorporación laboral en personas migrantes
}

\author{
Esteban BAKX BermúdeZ
}

Área de Desarrollo Familiar Programa de Interculturalidad. Municipalidad de La Reina. Av. Alcalde Fernando Castillo Velasco 9750, La Reina, Chile, mail:ebakx@mlareina.cl

\section{Reforma Migratoria y Política Nacional de Migraciones y Extranjería}

\section{Contextualización}

Según datos entregados por la Encuesta de Caracterización Socioeconómica Nacional (CASENInmigrantes 2015), al año 2015 en Chile era posible encontrar la presencia de 465.319 personas extranjeras, equivalentes al 2,7\% en relación con el total de la población existente en dicho país. Tal cifra, según datos proporcionados por el Departamento de Extranjería y Migración, aumentó exponencialmente a casi un millón de personas en el año 2017, lo que representa un 5,5\% del total de la población en Chile (DEM, 2018, p. 1).

Bajo este contexto de aumento de los flujos migratorios hacia el país, el actual gobierno del presidente Sebastián Piñera elaboró una nueva reforma migratoria basada en un plan de acción que contempla tres ejes específicos, los cuales buscan promover una migración segura, ordenada y regular.

La presente nota no revelará el plan de acción en detalle, sino más bien pondrá énfasis en las medidas que alteraron o alterarán la propuesta central del presente artículo, es decir, los mitos asociados a los procesos de incorporación laboral en personas migrantes. Esto permitirá tener una mirada más actualizada y clara sobre cómo llevar a cabo los procesos de incorporación laboral, así como también sobre los reales mitos existentes en relación con el tema en cuestión.

\section{Plan de acción}

a) Proyecto de Ley de Migraciones: El actual gobierno envió al parlamento con fecha 9 de abril del
2018 un nuevo proyecto de ley de migraciones, el cual contempla un conjunto de indicaciones del proyecto de ley presentado por el presidente Sebastián Piñera el año 2013 y algunos elementos del proyecto del año 2017 del gobierno anterior.

Dentro de las medidas que contempla el presente proyecto de ley, a modo general es posible mencionar: la creación de un Servicio Nacional de Migraciones, garantizar el derecho y acceso a la salud, educación, seguridad social y a otros beneficios de cargo fiscal, un nuevo sistema de revalidación y reconocimiento de títulos académicos y profesionales, la creación de un registro nacional de extranjeros y un cambio en relación con la operatoria para la solicitud y obtención de la visa temporaria (DEM, 2018, p. 3).

Esta última medida posee un impacto directo en relación con los procesos de incorporación laboral en personas migrantes. La actual ley de migraciones (Ley 1.094) da la posibilidad de que todo extranjero que tenga el propósito de radicarse en Chile pueda postular a un permiso de residencia estando en el país. En otras palabras, permite que muchas personas extranjeras puedan entrar a Chile en calidad de turistas y, si es que lo desean, puedan cambiar dicha calidad migratoria a residentes.

El nuevo proyecto de ley de migraciones, el cual aún está en discusión en el parlamento, propone que la visa temporaria pueda solicitarse única y exclusivamente fuera de Chile, prohibiendo que se pueda solicitar el cambio de calidad migratoria 
de turistas a residentes estando en el país (DEM, 2018, p. 3).

Esta situación a simple vista podría dejar obsoletos los mitos 4 y 5 desde el punto de vista administrativo, entendiendo que ningún extranjero tendría que tramitar su visa estando en el territorio nacional. Sin embargo, la medida podría también alterar los procesos de incorporación laboral en personas migrantes en Chile, especialmente para aquellas personas que ingresen al país en calidad de turistas, quienes no podrán trabajar formalmente puesto que la ley les prohibiría tramitar un permiso de residencia.

b) Medidas administrativas con efecto inmediato: Otro de los ejes específicos que contempla el plan de acción en materia migratoria del actual gobierno es la reformulación de los visados de residencia temporaria creados por vía administrativa. Esta reformulación contempla en términos generales la eliminación y la creación de ciertos visados.

Dentro de las visas creadas es posible mencionar la visa temporaria de oportunidades, visa temporaria de orientación internacional, visa temporaria de orientación nacional, visado consular de turismo simple para todo ciudadano haitiano, visado humanitario de reunificación familiar para todo ciudadano haitiano, visa de responsabilidad democrática para los nacionales de Venezuela y la eliminación a partir del 23 de abril del año 2018 de la Visa temporaria por motivos laborales (DEM, 2018, pp. 4-5).

La eliminación de la visa temporaria por motivos laborales altera los procesos de incorporación laboral en Chile, tanto para la comunidad migrante como para el mundo empresarial. Para este último es importante destacar que hasta que no se apruebe el nuevo proyecto de ley de migraciones, la única forma que se tendrá para poder contratar formalmente a una persona extranjera en calidad de turista será optando por la Visa Sujeta a Contrato, la cual dentro de sus especificaciones, acorde a los artículos 37 y 38 del Decreto Supremo 597 (Reglamento de Extranjería), exige que el contrato posea una clausula especial en virtud de la cual el empleador o patrón se compromete a pagar al trabajador y demás miembros de su familia que se estipulen el pasaje de regreso a su país de origen o al que se convenga. Dicha obligación del empleador o patrón referente al pago de pasajes subsistirá hasta que, terminado el respectivo contrato y suscrito el finiquito, el extranjero salga del país u obtenga nueva visación o permanencia definitiva.

A raíz de lo anterior, es sustancial mencionar que el mito $\mathrm{N}^{\circ} 2$ del presente artículo quedó obsoleto a propósito de la eliminación de la visa temporaria por motivos laborales, pasando a ser una realidad el hecho de que el empleador o patrón deba pagar los pasajes de retorno al país de origen del extranjero, en caso de quiebre de la relación laboral. Cabe mencionar que dicha exigencia se aplicará sólo para aquellos extranjeros contratados por medio de la Visa Sujeta a Contrato, todo extranjero que posea ya su cédula de identidad chilena (Temporaria o Permanencia Definitiva) se le puede contratar como a cualquier chileno más.

\section{Referencias bibliográficas}

MINISTERIO DE DESARROLLO SOCIAL (2016). CASEN 2015-Inmigrantes. Principales Resultados (versión extendida).

MINISTERIO DEL INTERIOR Y SEGURIDAD PÚBLICA (2018). Minuta: Reforma Migratoria y Política Nacional de Migraciones y Extranjería. 